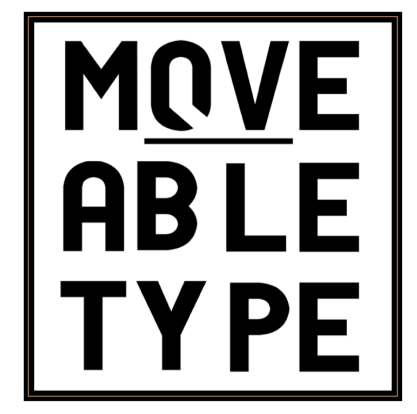

James Shirley and Early Modern Theatre: New Critical Perspectives, edited by Barbara Ravelhofer [Review]

Author[s]: Anthony Walker-Cook

Source: MoveableType, Vol.10, 'Peripheries' (2018)

DOI: $10.14324 / 111.1755-4527.091$

MoveableType is a Graduate, Peer-Reviewed Journal based in the Department of English at UCL.

(C) Anthony Walter-Cook 2018 COPYRIGHT. This is an Open Access article distributed under the terms of the Creative Commons Attribution License (CC-BY)

4.0https://creativecommons.org/licenses/by/4.0/, which permits unrestricted use, distribution, and reproduction in any medium, provided the original author and source are credited. 


\title{
TIMELY RESURGENCE
}

\section{ANTHONY WALKER-COOK}

\author{
James Shirley and Early Modern Theatre: New Critical Perspectives. \\ Barbara Ravelhofer (ed.) 2016. 233p. £110.00. \\ Routledge. ISBN 978-1472480361
}

In James Shirley and Early Modern Theatre: New Critical Perspectives Barbara Ravelhofer has collected twelve superb essays that put forward a strong case for studying James Shirley today. Full of discriminating details and wonderful moments of technical analysis, each essay presents a different cultural aspect of Shirley's work, emphasising his skill as a writer of both tragedy and comedy, and, often, unsettlingly in-between the two. Tied with The Complete Works of James Shirley (1596-1666) An Edition in 10 Volumes, also led by Ravelhofer with Teresa Grant and Eugene Giddens, the collection offers numerous opportunities for further study in Shirley's work, with Ravelhofer's 'Introduction' positing, 'If pressed to decide on one defining characteristic of Shirley's art, we might locate it in his willingness to see with, rather than look down on, a person, his ability to examine a situation from various perspectives'. ${ }^{1}$ Variety, certainly, is the pervading theme that comes from this collection.

In the opening essay, 'Time for James Shirley', Jeremy Lopez first bifurcates Shirley's position as the 'invisible man of the early modern dramatic canon' due to his historical position: his works look ahead to the 'comedy-of-manners' genre but also back to Jacobean revenge tragedy, and in his created worlds a culturally rich Caroline tone is formed through manipulating the conventions of antecedent dramatic forms. Lopez argues that the multiple moments of authorial self-consciousness and invisibility throughout Shirley's oeuvre are part of a process of assimilation wherein older works disappear. Offering a dramatist deeply informed by his own historical moment, Rebecca Hasler connects the apocalyptic fervour that seized seventeenth-century English society with Shirley's comedies, arguing that the latter adapts the narrative tropes of Revelation, including averting crisis through marriage and on-stage resurrections. Whilst further assertions of the dramatist's manipulation of other religious motifs are absent, Hasler's analysis of The Bird in a Cage, The Wedding and The Brother neatly offers a strong case for the

\footnotetext{
${ }^{1}$ Barbara Ravelhofer, 'Introduction', in James Shirley and Early Modern Theatre: New Critical Perspectives, ed. by Barbara Ravelhofer (London: Routledge, 2016), pp. 1-16, at p. 12.
} 
dramatist's following of an 'apoci-comedic' structure, positing the potential for further research into the intersection between religious studies and Shirley's work. Peter Happé then dissects the various representations of the court in Shirley's work, including an 'affectionately satiric' portrait of court life, a movement between levity and seriousness, set-pieces that rebuke popular opinions of the court and the notion of 'court face'. However, any conclusion of general disillusionment is undone by Shirley's movements: though he left the court for Dublin in 1636, within four years he returned, and thus Happé is left to tentatively imply the difficulty of Shirley's Irish experience encouraged him to try again with a London audience. Meanwhile, Shirley is frequently placed amongst many of the intellectual, cultural and political events of his period throughout this collection, with discriminating essays by Rachel Ellen Clark and Rebecca A. Bailey respectively examining his work in relation to his reception of Sir Philip Sidney's Arcadia and contemporary maritime debates (including the Ship Money Levy and piracy).

Ravelhofer's own contribution to the collection on Shirley's tragic works offers a variety of technical observations, bringing out the cadences of Shirley's verse in Love's Cruelty, The Traitor and The Cardinal. Amid this analysis Ravelhofer briefly records the experiences (and difficulties) of Guy Henry and Sonia Ritter, modern actors, when reading the works of Shirley and George Chapman to stress their rhetorical differences. It is a shame more of the media outputs of the James Shirley Project are not used as a way of proving the potential for Shirley to be produced today. ${ }^{3}$ Robert Lublin's essay on Shirley's Dublin plays picks up where Happé's finished, suggesting the playwright's troubles in Ireland were due to a lack of theatrical infrastructure within Dublin's cultural community. It is a clever argument for suggesting why Shirley failed. However, whilst many of the essays collected offer broader examinations of certain themes in Shirley's drama, Daniel Starza Smith and Jitka Štollová examine the Melbourne Manuscript (potentially a foul copy of Act 2, Scene 1 of The Traitor) and the character lists of The Politician respectively. Both reveal the fluctuating nature of Caroline theatre culture and deepen our understanding of Shirley's reception history. Philip West argues for the 'persistent concern in Shirley's work with the distinction between true poetic eloquence [...] and what he perceived as a fashion for outlandish, exaggerated, or obfuscatory

\footnotetext{
2 Peter Happé, “And you meane to rise at court, practise to caper': the Representation of the Court in James Shirley's Plays, 1631-36', in James Shirley and Early Modern Theatre: New Critical Perspectives, ed. by Barbara Ravelhofer (London: Routledge, 2016), pp. 48-58, at p. 48 and p. 51.

${ }^{3}$ See The James Shirley Project's website for more information: https://community.dur.ac.uk/james.shirley/
} 
language' by examining the dramatist's poetry. ${ }^{4}$ Looking to the poetry in Shirley's drama and that presented in Poems \&c (1646), concerns of excessive behaviour and linguistic decorum inform the previous work by Happé. Andrew Ashbee's analysis of the music in Shirley's oeuvre explains some of the functional purposes of the medium during Caroline stagecraft (it hid the creaking of moving scenery and symphonies allowed actors to make way for the dancers) and, whilst West celebrates the printing of Poems \& c, by contrast Ashbee validly highlights that the songs printed in the collection were done so at the expense of being separated from their musical scores. Marina Tarlinskaja worthily ends the collection with a piece on 'Versification from Shakespeare to Shirley: Implications for Performance', which, as per the tone of the rest of the collection, is replete with numerous telling details and analysis - especially Shirley's use of the suffix '-ion' compared to his contemporaries - and again posits Shirley as a transitional figure: he 'concludes the epoch of English Renaissance drama' but 'in its smoothness, Shirley's style seems to foreshadow post-Restoration drama'. ${ }^{5}$

In her introduction Ravelhofer explicates that critical interest in Shirley has come in waves, which first began with David Garrick's casting of Shirley as an archetypal English playwright, with the last book-length study being produced during the 1980s alongside several editions of Shirley's works. It is hoped James Shirley and Early Modern Theatre will prompt a new swell of interest in the dramatist with the release of affordable editions of Shirley's work, and there is an abundance of material to aid (and encourage) revivals and new adaptations. Shirley clearly dominated a transitional moment in literary history, and his return to the canon would certainly offer challenges of assignation to a particular period or movement. It is only through collections such as Ravelhofer's that Shirley can hope to return from the periphery, as it is certainly hoped that he will soon.

University College London anthony.walker-cook@hotmail.com

\footnotetext{
4 Philip West, 'The Drama of Shirley's Poems', in James Shirley and Early Modern Theatre: New Critical Perspectives, ed. by Barbara Ravelhofer (London: Routledge, 2016), pp. 153-166, at p. 153.

${ }^{5}$ Marina Tarlinskaja, 'Versification from Shakespeare to Shirley: Implications for Performance', in James Shirley and Early Modern Theatre: New Critical Perspectives, ed. by Barbara Ravelhofer (London: Routledge, 2016), pp. 193-210, at p. 209.
} 